\title{
MEMÓRIA VISUAL E IMAGINAÇÃO CRIADORA NAS ESTRADAS DE KIAROSTAMI
}

\author{
Alan Victor PIMENTA ${ }^{1}$
}

Resumo: Partimos do sentimento de inquietação provocado pelo contato com imagens cujo aspecto inconcluso sobressai ao desejo de entendimento racionalmente organizado. Neste entremeio, tencionamos alguma reflexão sobre uma forma de interpretação que não se desenvolva exclusivamente com base na obra, mas que a considere como suporte para os sentidos de encontro entre seu criador e aqueles que a veem e possibilite uma experiência estética que se expresse como relação de alteridade e estado de contemplação. Este artigo se faz como proposta para um modo de ver as fotografias de Abbas Kiarostami (Teerã, 1940), que transite pela cultura visual das iluminuras iranianas do século XVI, destacando elementos de sua composição como traços das imagens e narrativas tradicionais dos persas, e se misture aos significados dados a elas no presente de nosso diretor fotógrafo, para compor uma visão imersa na memória visual do artista e na imaginação criadora do espectador.

Palavras-chave: Fotografia. Abbas Kiarostami (1940). Educação visual. Imaginação criadora. Iluminura Persa.

\section{Introdução}

As imagens nos ensinam modos de ver. Cada uma, à sua maneira, figura gestos e registra o encontro de um corpo com o mundo. Aquelas produzidas por artistas do passado, quando reverberam na produção presente de outros, sem que se tenham conhecido, mesmo tendo vivido em épocas e lugares distintos, participam do mesmo corpo e do mesmo espaço/tempo. Mas também deste encontro participamos nós, que os vemos em nosso presente.

Este texto buscará modos de ver algumas das fotografias do iraniano Abbas Kiarostami (Teerã, 1940), acompanhadas por conceitos sugeridos por seus próprios filmes e textos, e visitará nessas fotografias a memória histórica sobre a produção de imagens neste local, que foi a Pérsia no século XVI, por meio das iluminuras grafadas sobre os poemas de Nizami.

A arte de Kiarostami encontra expressão em diversas linguagens. Graduado em Belas-Artes pela Universidade de Teerã, exercitou a pintura e a poesia, ganhou

${ }^{1}$ UFSCar - Universidade Federal de São Carlos. Centro de Educação e Ciências Humana - Departamento de Educação. São Carlos - SP - Brasil.13565-905 - russo333@ hotmail.com 
expressão internacional como cineasta e, desde algum tempo, tem atuado como fotógrafo. Sua produção imagética tem forte traço autoral e a presença deste realizador é marcante em todas as formas de expressão reunidas em seus filmes, de modo que é possível trabalharmos sua produção fotográfica separadamente, mas também atentando à visualidade de suas obras cinematográficas.

Algumas das características mais marcantes deste fotógrafo diretor são relacionadas à maneira como possibilita ao espectador participar ativamente na formação do sentido de suas imagens, construindo narrativas de forte apelo poético, cujo entendimento permanece aberto, transitório, inconcluso. Em Caminhos de Kiarostami, Jean-Claude Bernardet (2004) expõe estas marcas como modernas estratégias cinematográficas, que integram à obra a sensibilidade de quem a vê. Há, no entanto, possibilidades de interpretação deste modo de compor cenas e contar estórias, fílmicas ou fotográficas, que abordem os processos históricos aí envolvidos e a educação visual do autor como ser social de sua época, que remetam o espectador à ação fluida da memória visual da Pérsia iraniana. Não supomos que o percurso entre o objeto artístico e a interpretação deva acontecer por determinação do contexto histórico da obra; mas que esta memória pode sugerir caminhos aos olhos que a percorrem e reverberar sentidos novos no presente.

\section{A imaginação criadora}

"Imaginar é exercer uma sagrada liberdade cívica e política." (ALMEIDA, 1999, p.01).

Em determinados contextos, de natureza idolátrica, os objetos artísticos poderiam ser entendidos como possuidores de valor por si mesmos, não necessitando que se considerasse aí a relação com as pessoas - de modo semelhante ao que acontece com as relíquias religiosas, cujo poder emanador independe da presença do fiel. Ainda que aceitássemos esta possibilidade como real, tais objetos assim o seriam por estarem investidos desse significado por aqueles que os olhassem, rodeassem, ou mesmo se ausentassem, de modo que o "valor natural" da obra permaneceria constituído em relação ao espectador - posicionado como receptor, nesse caso.

Quando a relação com as obras artísticas é partilhada como experiência estética, torna-se possível que aquele que vê enxergue algo além das formas imediatas. É possível ao observador receber da imagem que vê, imagens outras, que participam de 
sua composição como memória do passado do artista; mas também imagens de si, daquele que olha, e cuja memória produz sentidos sobre o que vê. E então não se vê somente a obra, ou a si mesmo, mas a si no mundo e ao mundo em si, na história da obra e na história dos olhares já lançados sobre ela.

Se a arte, além de estar no objeto, está nos olhos de quem o vê, sua compreensão é histórica e social, ao mesmo tempo em que é individual. Deste modo, não só a interpretação de uma mesma obra pode variar conforme diferentes espectadores, como a obra vista novamente após um intervalo de tempo recebe diferentes significados. Se o sentido da obra estivesse unicamente nela, na própria obra, o mesmo significado afloraria em todos os espectadores e não se alteraria no decorrer do tempo. Se assim fosse, a obra se renderia ao conceito e a uma grande sorte de mensurações a valorações.

Interpretar a obra como se fosse ela a fonte emanadora do sentido, “[...] apenas por sua mensagem explícita, visível ou dedutível pela história narrada, é também uma interpretação incompleta, um naturalismo científico, mesmo que essa interpretação venha fundamentada em teorias estéticas, sociológicas e políticas.” (ALMEIDA, 1999, p.38). Ao explicar as obras como expressão de conceitos e categorias predeterminadas, "e não como uma ideologia que se faz em forma de alegoria" artística, essas interpretações submetem as obras a comprovar as teorias.

Utilizar teorias lógicas e claras para explicar um afresco [...], ou um filme é acreditar que este tipo de obra tenha também uma origem lógica e clara, mesmo que não a deixe transparecer. Como se o construto mental que dá forma lógica à teoria explicativa fosse preexistente ao objeto que ela deseja interpretar. A interpretação deve partir do caos aparente da imagem, encarar o mistério dos intervalos significantes e valer-se também do caos das teorias, não ter medo do seu aparente conflito. (ALMEIDA, 1999, p.38-39).

É possível entender nossa relação com as diferentes linguagens artísticas não apenas como conteúdos a serem decifrados, entendidos por completo e explicados de maneira direta. Embora este seja um procedimento possível, são também alegorias cujas origens históricas existem e podem ser consideradas, são mensagens que se deslocam no tempo e aparecem no presente de quem as vê, integrando-se à memória em estado de contemplação. Este fatal intervalo entre o objeto e os olhos é que tenciona a ideia de uma interpretação inteiramente objetiva.

Em “A obra de arte na era de sua reprodutibilidade técnica", primeira edição de 1936, Walter Benjamin (1983) associa a perda da possibilidade contemplativa frente à 
arte a diversos fatores, entre eles, às legendas explicativas adicionadas por certas revistas, condicionadoras do sentido que o espectador atribui à imagem. Outro fator de relevância seria o "apelo dirigido às massas pela obra de arte", envolvendo aí certo projeto político do século XIX que, ao mesmo tempo em que amplia o acesso às obras, por meio da institucionalidade dos museus e casas de exposição, também difunde modelos interpretativos de objetividade visual. Os adventos da fotografia e do cinema, aliados ao seu entendimento como produtores de imagens reais, "sem a intervenção das mãos do artista”, são expressões desta ideologia que não só naturaliza o fenômeno visual, como consagra certo modelo de interpretação que desconsidera a ação do espectador sobre o que é visto, contribuindo significativamente na construção do mito da passividade visual - atributo das noções de objetividade.

Sobre este ponto, a obra de Kiarostami é expressão de seu profundo sentimento de inadequação, ao propor enredos, ou mesmo imagens estáticas, de claro apelo a uma “estética relacional” (BERNARDET, 2004, p.52, grifo do autor). Este modelo não apenas privilegia, como toma por fundamental a participação do espectador. As imagens e histórias contadas são de tal forma inacabadas que, aos espectadores, não resta outra possibilidade a não ser completá-las com sua própria imaginação. Esta forma de ação sobre a imagem pode ser mais bem compreendida à luz do conceito de mundo imaginal, tal qual formulado pelo orientalista Henry Corbin (França, 1903-1978). Imaginal é diferente de imaginário no sentido de que a este ultimo tendemos, no ocidente, a atribuir qualificativos próximos aos de fantasioso e irreal, enquanto imaginal preserva a ideia desenvolvida por pensadores como Suhrawardi (Irã, 1154-1191) (CORBIN, 2007) e Ibn’Arabi (Múrcia - Espanha, 1165-1240) sobre a capacidade imaginativa como a correspondente interna para o sentido da visão, sendo dotada de realidade tal qual sua equivalente externa (CORBIN, 2006). Nesta perspectiva, o ato de ver não é algo que se faça apenas "de fora para dentro", mas ação também como atividade de quem vê.

Seguindo este princípio, a ideia de que as imagens, mesmo as histórias, necessitam da atividade criadora do espectador para que se completem torna-se uma constante, não apenas nas imagens de Kirostami, mas também na de outros artistas. Na verdade, esta é uma disposição que, se iniciada no próprio espectador, pode ser estendida a qualquer obra de arte. No caso de nosso fotógrafo iraniano, ajuda a tomar como prazer o estranhamento inicial de que suas imagens e histórias se configurem muito mais como perguntas do que respostas. Instigar o espectador às questões significa um ato de profundo engajamento político, não por uma causa específica, mas por 
exercício da liberdade, imaginal, sem a qual a ação artística implicaria doutrinar o público.

\section{Kiarostami - caminhos que bifurcam}

A obra cinematográfica de Abbas Kiarostami tem se tornado cada vez mais conhecida e prestigiada no Brasil, tendo sido tema de Festivais de Cinema, modismos e discussões acadêmicas. Sua linguagem cinematográfica abre novas possibilidades para se pensar o cinema narrativo e tenciona os limites entre a ficção e o documentário. Em atenção a este ponto, Jean-Claude Bernardet ressalta que é o princípio de incerteza que rege a produção deste cineasta: o espectador não sabe de todo o que está vendo. "Kiarostami transmite informações a conta-gotas e mantém seu espectador subinformado: é uma de suas estratégias fundamentais." (BERNARDET, 2004, p.51).

É possível contar uma série de exemplos em suas obras fílmicas. Em Vida e nada mais, o diretor de Onde fica a casa do meu amigo? propõe-se ir até outra cidade saber se as crianças que atuaram no filme sobreviveram ao terremoto, mas o nome da cidade não é revelado no filme logo de imediato, o que acompanhamos é a viagem já em andamento e não temos a informação do destino. Ao passar pelo pedágio, o diretor pergunta sobre a estrada. $\mathrm{O}$ cobrador responde que ele tinha feito a mesma pergunta na véspera. O motorista explica que no dia anterior pretendia ir a Rudbar, mas que, como a estrada estava interrompida em Manjil, precisou voltar. Como a passagem é liberada apenas para veículos que levam mantimentos, o filho sugere mostrar a fotografia dos garotos e dizer que levam mantimentos para as vítimas. Seguindo estrada, e após indagar por diversas vezes, para diferentes pessoas, sobre o caminho a seguir, ele pergunta a mulheres na estrada sobre como ir a Koker, e esta é a primeira vez que o destino da viagem é mencionado, a vinte e seis minutos do início do filme, passado um terço da projeção total.

Desconhecendo o destino, é o trajeto, o próprio movimento, que ganha evidência e por meio dele a história é encenada. Uma observação importante sobre este fluxo é que ele nunca se dá em linha reta nem por vias principais. As estradas de Kiarostami são sempre sinuosas e repletas de contratempo.

A desinformação dilata o tempo. Longe do tempo vetorial das narrativas tradicionais, nas quais conhecemos os objetivos dos personagens, mas não o resultado de suas ações, o parco reconhecimento da razão de ser das ações que vemos os personagens 
praticar gera como que um tempo sem finalidade, um tempo em meandros, como o espaço da trajetória que não se dá em linha reta e se espalha em pausas e desvios. (BERNARDET, 2004, p.54).

Este modo de narrativa incide de forma poderosa sobre o espectador. A desinformação sobre as motivações dos personagens cria a necessidade de que se preste muito mais atenção a tudo o que se vê, a tudo o que é dito, já que qualquer detalhe se torna essencial na composição da história. O espectador também participa do processo de busca evidenciado pelas indagações do personagem-diretor desde a primeira cena de Vida e nada mais (1992). Algo semelhante acontece em diversos outros filmes de Kiarostami, a parcimônia na administração da informação dá potência às imagens e ao papel que cumprem na montagem do filme. Se, em $O$ gosto de cereja (1997), por exemplo, conhecêssemos já de antemão as intenções do senhor Badii ao passar tanto tempo em seu automóvel à procura de alguém que realize um trabalho tão incomum, informação que nos é dada após vinte e quatro minutos do início do filme, é bem possível que a construção desta revelação não alcançasse uma proporção tão intensamente perturbadora.

A incompletude é outro princípio fundamental na obra de Kiarostami: as ações não chegam a um desenlace, ficam em aberto. O espectador não tem resposta às indagações nem à resolução dos problemas, mas o não saber, a hipótese, a dúvida. O importante, como traço fundamental desta obra artística, é o movimento que se desenrola no tempo, não a finalidade.

Em O gosto de cereja (1997), não temos certeza se o senhor Badii foi bemsucedido em seu objetivo e assim por diante: o menino de Onde fica a casa do meu amigo? não encontra o amigo; o diretor, em Vida e nada mais (1992), não encontra os meninos, ele ouve dizer sobre o estado deles, mas esta incerteza não é resolvida; não sabemos o destino do casal em Através das oliveiras; e quanto ao esperado ritual fúnebre de $O$ vento nos levará, não será visto e nem filmado. Os objetivos, que levamos tanto tempo para entender, não são alcançados, ficam em suspenso.

O que fica não é a resposta a alguma indagação, a resolução de algum problema, mas o não-saber, a hipótese, a possibilidade, a dúvida. A certeza, nunca. O que fica é o movimento que se desenrola no tempo, não a sua finalidade. O que importa na busca é o seu dinamismo, não o seu objetivo. Entendemos, então, como nesse quadro uma rua sem saída pode ser angustiante: ela fecha o espaço, interrompe o movimento. Quando Puya [em Vida e nada mais] pergunta ao pai o que é uma rua sem saída, este, que vinha dialogando com o filho sobre 
o caminho, não responde e, com o rosto tenso, continua guiando. A pergunta de Puya encerra o diálogo. O mundo de Kiarostami não se fecha sobre si mesmo. (BERNARDET, 2004, p.57).

Interessa-nos pensar a forma, assumida em imagem, para estas duas características referenciais em Kiarostami, os princípios de incerteza e incompletude. A necessidade de que o recorte do campo visual não simule um fechamento do espaço sobre si mesmo é algo de recorrente nas imagens fotográficas e fílmicas deste artista. Esta materialidade da abertura do campo visual, seja pelo enquadramento, seja pela sequência, prescinde de apelo ao recurso do campo-contracampo, que, mesmo quando empregado, é coordenado no sentido de ampliar a participação do espectador e quase nunca se fecha na bipolaridade do diálogo entre dois personagens. Esta configuração da imagem, que libera os olhos do sentido fechado mesmo quando não enquadra a linha do horizonte e foca apenas o chão, caracteriza sua obra artística e politicamente.

\section{Fotografia}

Conhecem a história do menino que pediu ao pai para lhe mostrar uma floresta?

O pai concordou e, quando chegaram, o pai perguntou se o menino avistava a floresta. Admirado, o menino disse: 'Vejo, mas são tantas árvores na frente que quase não consigo ver a floresta. (KIAROSTAMI, 2004, p.186).

Na série fotográfica “As estradas de Kirostami 1978-2003”, a singularidade dos elementos de cena, quase desprovidos de significantes internos à composição, não chega a definir qualquer direção a ser percorrida pelos olhos de quem as vê, "a despeito de deixarem claro que o destino está ali sempre em jogo" (LISSOVSKY, 2014, p.96).

Os primeiros anos da Revolução Islâmica refrearam nosso trabalho. Certo dia em que não tinha o que fazer, comprei uma câmera Yashica bem barata e tomei o caminho da natureza. Eu queria me confundir com ela. Ela me conduzia. [...] Minhas fotografias não são o resultado de meu amor à fotografia, mas do amor que dedico à natureza. [...] Durante muitos anos, eu deixava a cidade e me sentia muito melhor. [...] Para quem nasceu em um apartamento e está habituado aos grandes edifícios, a natureza tem uma significação inteiramente diversa. Em minha opinião, essa natureza é o oposto da natureza humana e de suas necessidades. Nós tendemos, muitas vezes, a esquecer essa realidade. (KIAROSTAMI, 2004, p.90).

${ }^{2}$ Kiarostami (2004). 
Ishaghpour (2004, p.90) chama atenção para a ambiguidade da expressão "natureza oposta à natureza humana", utilizada pelo cineasta. Ela pode partir de uma ideia geral sobre a "natureza" alienante da vida moderna citadina, estranha à verdadeira natureza do homem. Ou então "significar o 'inteiramente outro' da natureza que partilha do sagrado, oposta ao homem na medida em que este, mesmo exilado, não aspira mais a ela, a reencontrar a unidade e a intimidade nessa contemplação-criação que revela sua beleza". A paisagem, disposta desta maneira nas fotografias e filmes de Kiarostami, configura-se como alteridade, já que para dar visibilidade à beleza da natureza, é preciso que se esteja em exílio.

Na natureza do exílio, o espectador vê sua própria ausência: “[...] a natureza, com o indizível de seu mistério, tendo existido antes dele e lhe sobrevivendo, dispensao perfeitamente [...]" (ISHAGHPOUR, 2004, p.90). Do lugar da contemplação, os olhos percorrem a beleza estrangeira e partilham da experiência singular da própria mortalidade. Do lugar de seu recolhimento, o olho exilado só vê graças a distância e ao silêncio com que vai ao encontro da paisagem vista:

[...] por sua intimidade essencial com o numinoso e seu distanciamento de toda condição humana determinada, de todos os vínculos exteriores, por sua própria ausência para si mesmo e sua solidão absoluta. Assim, o próprio efêmero, o 'tempo', torna-se imagem da eternidade. (ISHAGHPOUR, 2004, p.90).

Se considerarmos, no entanto, a natureza de modo desnaturalizado, entenderemos que ela é fruto da cultura, principalmente quando é o exílio em seus domínios, o que possibilita ao viajante a redescoberta de suas próprias fontes. A própria concepção de paisagem campestre, na pintura, foi invenção de citadinos, e não de camponeses. Este aspecto nos sugere que uma paisagem aponta de modo mais incisivo para a realidade daquele que a contempla. Kiarostami, ao abrir a angulação de seus enquadramentos, aproxima da natureza os camponeses que filma/fotografa, em tal intimidade de trabalho na terra que seria difícil imaginá-los separados deste contexto, de tal modo que as linhas e tons que constituem seus corpos parecem a continuidade daqueles que perfazem e, assim, os integram à paisagem. "A paisagem só se torna visível por ser o longínquo." (ISHAGHPOUR, 2004, p.91). É aquele que a vê em recorte fotográfico e lança sobre ela seu olhar que recebe, em devolutiva, questões de outra ordem, ideias trespassadas que o remetem ao 'outro'. Na fotografia, tudo é forma 
e toda a forma é conteúdo, sendo inseparáveis essas definições quando se trata da visão fotografada. Pois olhar a paisagem revelada sobre o papel fotográfico pede que os olhos se modifiquem em outros olhos, no olho do outro, "outro saber, e ainda esse apagamento de si para que o mistério da natureza se torne visível". "Não se deve, porém, esquecer que é difícil ascender a este estado privilegiado. É preciso saber olhar, saber ver. Tudo se resume na maneira de ver. O segredo reside no conhecimento desse modo de visão, de olhar." (ISHAGHPOUR, 2004, p.92).

Em grande parte da obra fotográfica de Kiarostami, vemos um elemento que se destaca com relação ao todo composto pela paisagem, uma árvore, uma pessoa ou uma estrada vazia. Este direcionamento singular ressalta uma escolha estética do fotógrafo, mas também uma escolha conceitual. Uma única árvore é mais dos que uma árvore em conjunto com outras, porque o conjunto corresponderia a outro conceito, ao do coletivo de árvores, e não carregaria mais a singularidade de uma árvore, para a qual deveria estar retratada de forma solitária, suspensa na paisagem.

Fotografia 1 - As estradas de Kiarostami 1978-2003”...

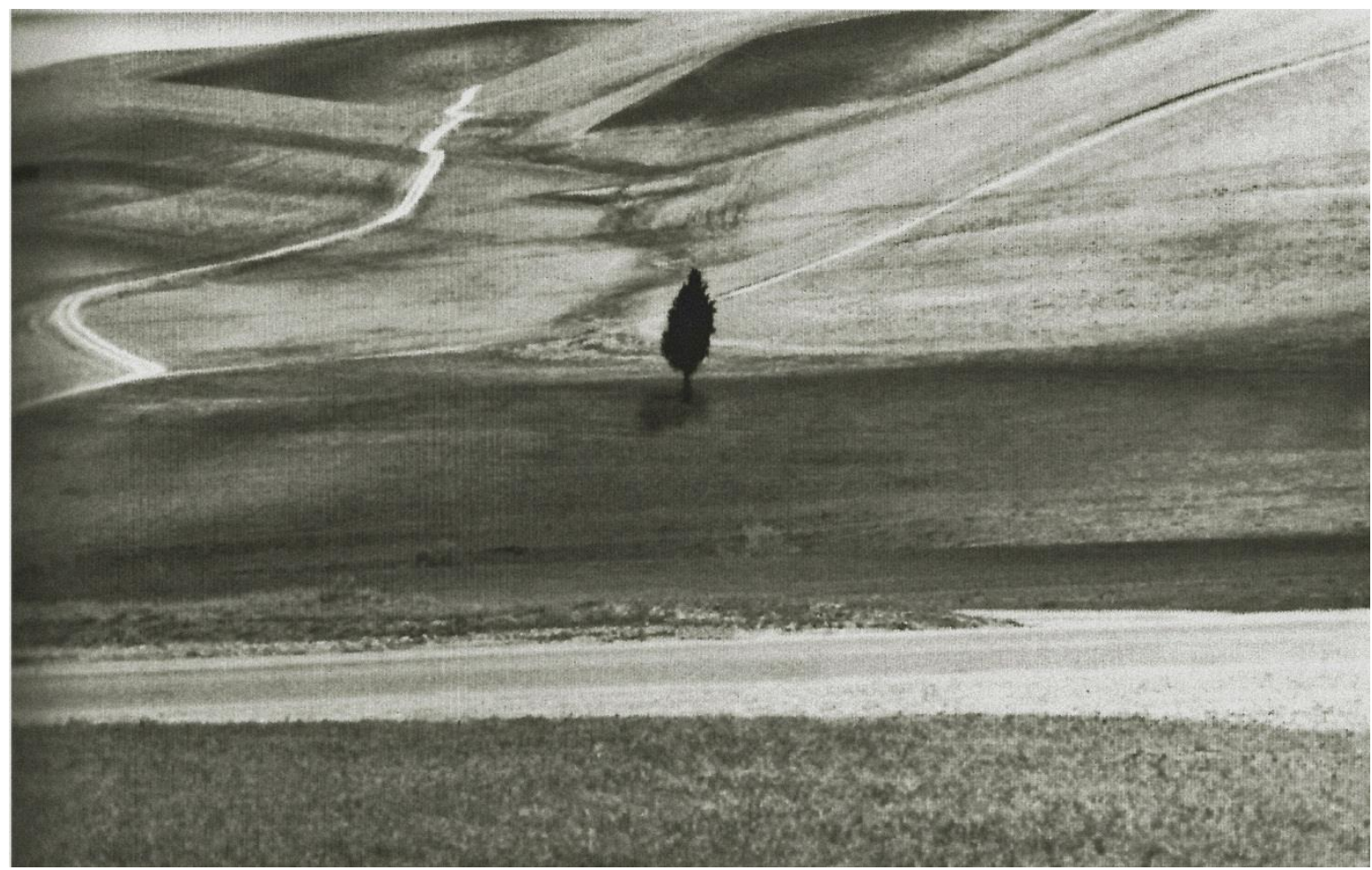

Fonte: (KIAROSTAMI, 2004).

A visão ativa, de imaginação, alcança na fotografia, em qualquer das fotografias de Kiarostami, o ponto de encontro entre caminhos que bifurcam, apontando a árvore 
que, por mais que o seja, não pertence àquela paisagem de modo natural, à paisagem fotográfica, sobreposta à paisagem fotografada. É uma árvore e uma outra árvore, um outro espaço além do horizonte da visão e que a devolve à imagem que constitui na orientação interna de quem a vê. É uma árvore e uma não árvore. Desta, a escuridão se espalha em sombra e demarca o chão da terra, expandindo-se até se tornar uma marca do céu, como em uma transfiguração. A chave: e como seria se não houvesse a árvore?

O importante é o enquadramento. De qualquer coisa. Quando tiro uma fotografia, pergunto-me se irei revelá-la ou não. Normalmente hesito, mas depois acabo por fazê-lo de qualquer maneira. No instante preciso em que coloco o instantâneo em uma moldura com um passe-partout, ele se torna subitamente mais atraente, e quando olho para ele através do vidro da moldura, acho-o perfeitamente plausível. Portanto, creio que a ideia de enquadrar um objeto numa imagem é tão importante quanto o conteúdo. Ao escolher e enquadrar alguma coisa, nós lhe damos a dimensão da importância que provém do fato de a termos selecionado. No momento em que se seleciona algo, lhe conferimos um valor adicional que o distingue de toda e qualquer outra coisa. (KIAROSTAMI, 2004, p.178-179).

Grande parte da composição fotográfica de Kiarostami, e mesmo nos filmes, a disposição entre os elementos da cena é paralela, com camadas dispostas de faixas de terra, areia, água, árvores, estradas e mourões. São como faixas visuais entre quem vê e o além da imagem. Esta disposição em paralelo é, em grande parte, o que constitui o aspecto de frontalidade na composição das imagens, o que funciona como modo de desnaturalização da organização tridimensional do espaço, se furtando à profundidade de campo em perspectiva, que é própria à temporalidade da história e da ação. Temos então um tempo em suspensão.

É também possível que a disposição paralela dos planos seja a autora da atmosfera de tranquilidade que conduz ao silêncio. Mesmo nas imagens em que a tempestade se arma, as nuances de tom, os claros e os escuros que se misturam em contiguidade dificilmente favoreceriam um desdobramento sinfônico de contrastes contrários. 
Fotografia 2 - As estradas de Kiarostami 1978-2003

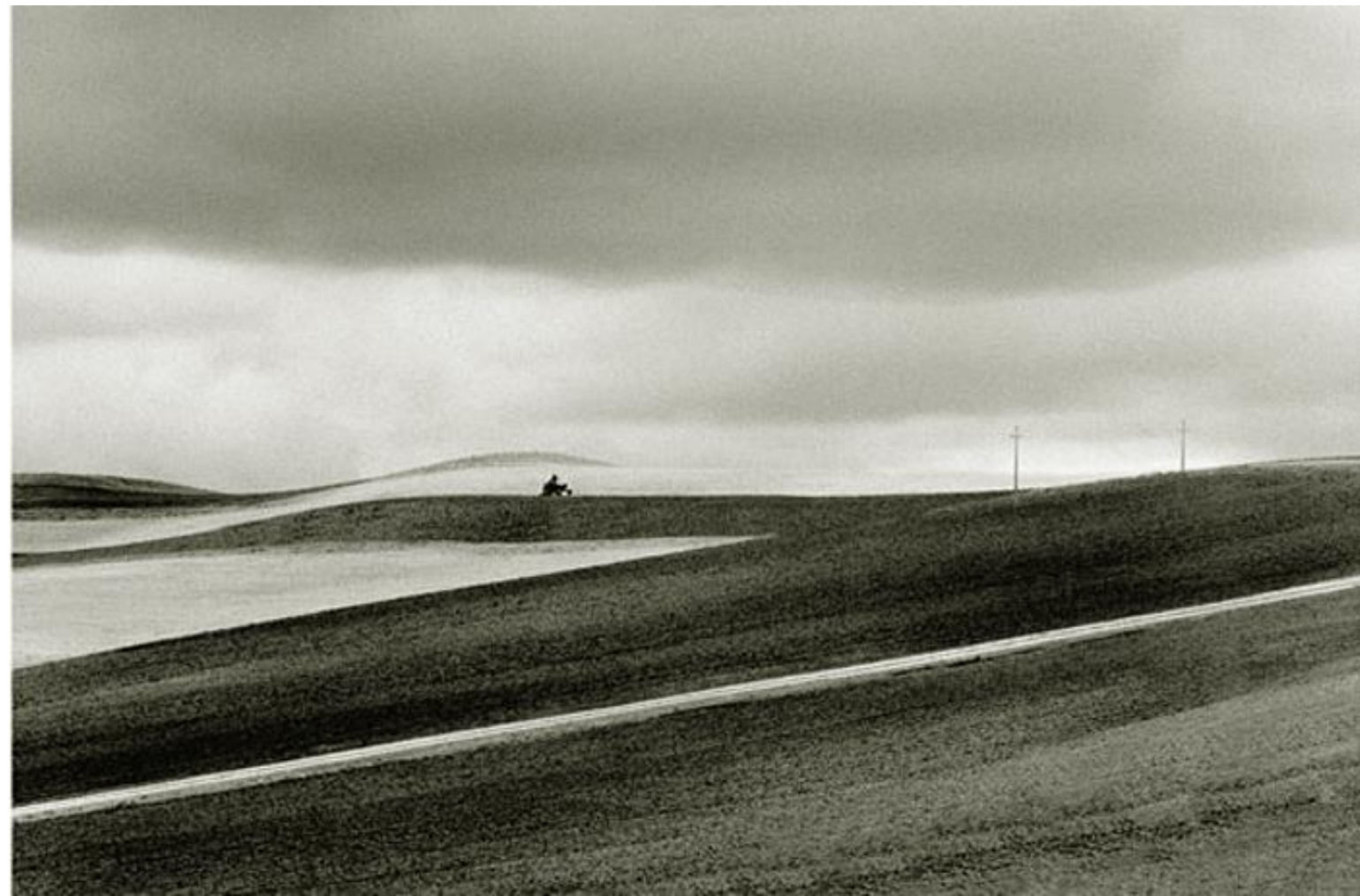

Fonte: (KIAROSTAMI, 2004).

As iluminuras que veremos adiante atingem uma esfera harmônica sob outros procedimentos. A pintura, diferentemente da fotografia, se realiza por obra da memória e da técnica manual do pintor. Não que o ato fotográfico prescinda destes elementos de intervenção, como da participação ativa do fotógrafo antes, durante e após a captura. No resultado final obtido nas estradas de Kiarostami, no entanto, o caráter de transcendência com o qual a natureza se apresenta se faz por modo de sua própria presença, sendo este modo de presença, o sentimento - ou mesmo o sentido de "desaparecimento" - do fotógrafo (ISHAGHPOUR, 2004, p.95). Este sentimento é verificável nas imagens, rarefeitas, cuja linguagem se aproxima de um minimalismo contido. Esta impressão, sem dúvida, existe, mas não deixamos de notar que existe aí uma simplicidade essencial, mas de caráter marcadamente estético. Kiarostami e a fotografia em geral são tão artificiais quanto qualquer outro artista, só que este modo de composição rarefaz a densidade de seu artifício.

Walter Benjamin, por diversas vezes, chamou atenção para o processo destruidor da "aura" por obra da reprodutibilidade técnica operada pela fotografia. A percepção de que "as coisas são o que são", e não aquilo que nossa visão "coisificadora" deseja que 
sejam, é parte da "experiência da aura" em Benjamin. Para o pensador, é implícita ao olhar a expectativa de ser correspondido por aquilo que se oferece. "O que na daguerreotipia devia ser sentido como desumano, diria mesmo mortal, era o olhar dirigido (além do mais, longamente) ao aparelho, enquanto este acolhe a imagem do homem sem lhe retribuir um olhar" (BENJAMIN, 1983, p.52). A satisfação de tal expectativa alcançaria, pelo olhar, a experiência da aura.

Em "Sobre a linguagem geral e sobre a linguagem dos homens", texto que Benjamin escreve em 1916, Lissovsky (2014, p.30, grifo do autor) reconhece a tentativa de delimitar um campo em que uma "outra" linguagem pudesse se contrapor à "concepção burguesa da língua" - para a qual "a palavra é meio de comunicação, seu objeto é uma coisa e seu destinatário é um homem". Esta linguagem "outra" remeteria às concepções da mística judaica sobre a palavra, cuja origem è remetida à palavraadâmica, a linguagem do bem-aventurado. Esta forma de linguagem não poderia ser, evidentemente, legada exclusivamente ao seu aspecto de contrato social, por meio do qual as palavras não guardam mais a potência das coisas. Benjamin aponta para uma forma de linguagem por meio da qual "se irradia, sem som e na muda magia da natureza, a palavra divina" (LISSOVSKY, 2014, p.31).

É no caráter de uso nomeador e instrumental que a linguagem se degrada. Ainda segundo Benjamin, seria necessário ver as coisas como se elas nos vissem para se atentar à sua linguagem. Esta postura de abertura à perceptibilidade caracteriza um importante passo na experiência da aura.

O advento da fotografia ocasionou, para Benjamin, grande parte da mecanicidade na linguagem visual, por conta de seu caráter de reprodutibilidade técnica. A fotografia, nesta concepção, traria as coisas para a proximidade, colocando-as à disposição de quem a vê. Neste caso, o espectador não mais se força a "levantar o olhar", a se recolher num átimo de tradução do intraduzível, de reinvenção da linguagem - fatal intervalo de encontro com a poesia. Por este motivo, a reprodutibilidade técnica seria impeditiva da fotografia como meio para a contemplação, justamente por reduzir o objeto à mera singularidade visual de ser traço de si mesmo. Há, no entanto, algo de específico em algumas obras fotográficas que nos devolvem a esta discussão com fôlego renovado. A paisagem de Kiarostami está entre as exceções, pois ao mesmo tempo em que suscita no homem "o sentimento de sua própria finitude, a natureza, por seus retornos cíclicos, abole o tempo". Nesta condição, os elementos de cena que compõem as paisagens são algo além deles mesmos. 
O sentimento da contemplação, então, se torna possível pela relação de "restituição" que o espectador estabelece com a paisagem e que "[...] não consiste apenas em devolver à natureza o que se recebe dela, mas ainda em permitir que a própria recepção seja uma ocasião para que a natureza se torne presente no recuo mesmo de sua aparição. Que a arte queira ser o espelho em que o mundo se olha." (ISHAGHPOUR, 2004, p.96).

\section{A iluminação persa - quando o tempo é feito espaço}

Neste esforço reflexivo sobre a memória histórica legada à fotografia de Kiarostami como educação visual, levamos em conta as iluminuras persas produzidas no século XVI sobre alguns poemas escritos por Nizami no século XII ${ }^{3}$. Estas imagens não foram pensadas como formas a acompanhar os textos escritos por Nizami, como as ilustrações modernas. Elas são dispostas na página seguindo uma dinâmica de relação com o texto, como se ambos pudessem ser vistos ao mesmo tempo, dispostos um sobre o outro. Desta maneira, o sentido sugerido pelas iluminuras não é subordinado àquele dado pelo texto e vice-versa.

\footnotetext{
${ }^{3}$ Nizami ou NezamiGanjavi (1141 - 1209), foi poeta e escritor persa amplamente apreciado por todo o mundo árabe. Sua poesia demonstra grande familiaridade do autor com a literatura persa e árabe de tradição popular oral e escrita, mas seu prestígio adveio principalmente de sua habilidade em fundir esta tradição a elementos dos mais variados campos, como matemática, astronomia, astrologia, alquimia, medicina, botânica e filosofia, constituindo uma exegese do Corão. Seus poemas são fonte de estudos de história, ética, filosofia, música e artes visuais, além do sufismo xiita.
} 
Fotografia 3 - Nushirvan Ouve as Corujas no Palácio em Ruínas

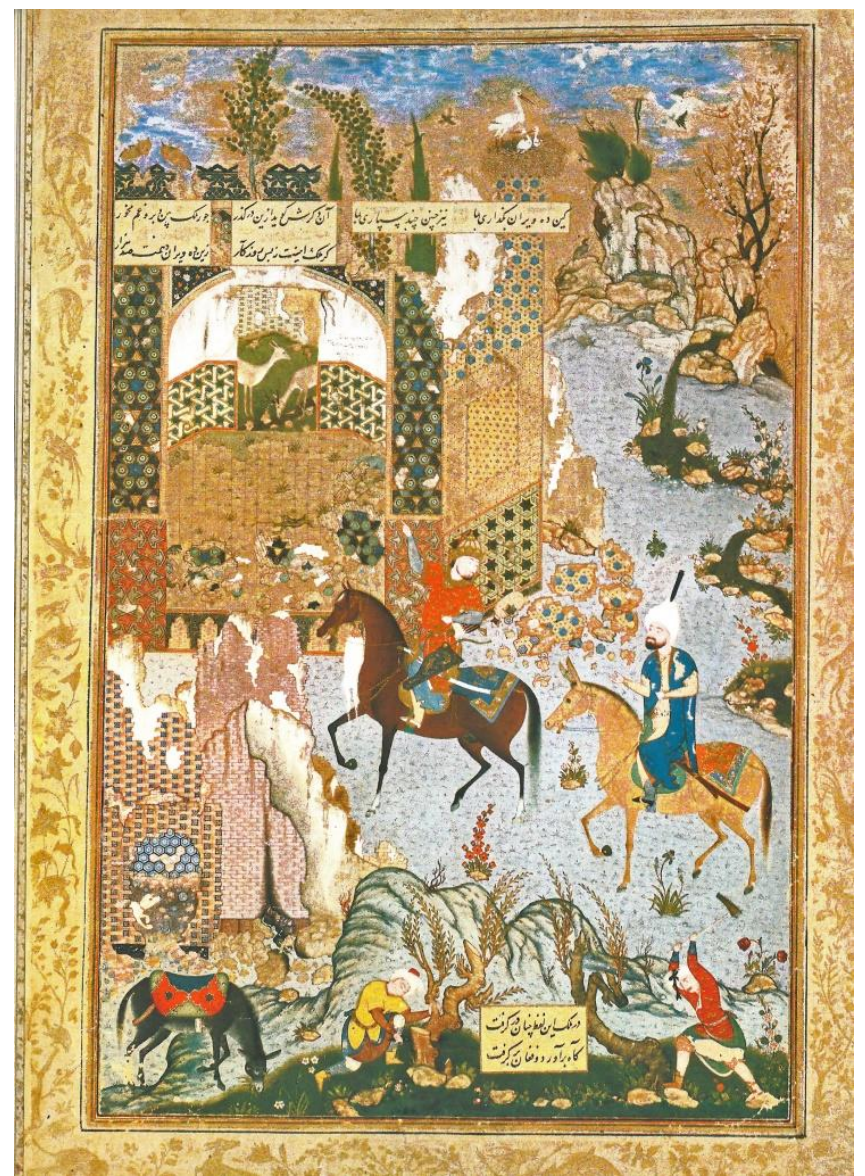

Fonte: AqaMirak ${ }^{4}$

Nesta imagem, o rei Nushirvan passeia com seu vizir por antigas ruínas. Ao passar, ele houve o piado das corujas sobre o muro do palácio e pergunta: "Que segredos elas dizem uma à outra?". "Perdoe-me, ó rei, por repetir suas observações [das corujas]", respondeu o vizir. "Uma delas está dando sua filha em casamento à outra e exige um dote adequado. 'Dê a ela', ela diz, 'esta vila em ruínas, e uma ou duas outras que ficaram à mercê.' 'De qualquer modo', responde a outra. 'se nosso nobre regente continuar no curso atual, deixando seu povo perecer na miséria e negligência, terei prazer em dar não duas ou três, mas cem mil casas em ruínas!’”.

As imagens agregam motivos ao diálogo, levantando questões sobre a glória do rei Nushirvan, como guerreiro e/ou caçador (a supor pela espada e arco presos à sua cintura), e a relação estabelecida com seu povo. Não é necessário que imagens e textos 
completem este entendimento de maneira ilustrativa, nem que os escritos evidenciem esta relação, já caracterizada pelo aspecto da vila e pela fala final de uma das corujas.

Esta prancha é atribuída a AqaMirak (Qazvin, Irã, 1520 - 1576) e representa o momento clássico na história da arte Safávida (Irã, 1501 - 1722). Tecnicamente equilibrada, esta iluminura combina elementos de entendimento racional às expressões emocionais profundamente cativantes, constituindo um exemplar do romantismo desta fase.

Na parede interna da ruína, há uma inscrição: "Erguido de um coração deserto, daqueles privados de felicidade, não há lar melhor que este. Escrito por Mi.... Musavvir, 946 A.H. (1538-1539 d.C.)." A assinatura, em parte danificada por descamação, é aparentemente a de Mir Musavvir $(1510$ - 1555), cujo filho Mir Sayyid'Ali provavelmente trabalhou nesta iluminura, que foi projetada e executada em grande parte por AqaMirak, um mestre mais velho, que teve todo o crédito por ela.

A imagem é configurada segundo uma ordem de perspectiva paralela que sugere aos olhos uma movimentação em espiral. Diferentemente da perspectiva europeia clássica, este direcionamento não subordina os olhos a um único caminho, a um ponto de fuga único. A dimensão espacial não se configura tridimensionalmente e, por conseguinte, não determina quadrantes temporais no interior da obra, denotando a origem dos movimentos e subordinando a cena a uma dinâmica expressiva de causa e consequência. Se os olhos percorrem a imagem sem que sejam direcionados a um ponto final, a finalidade das ações dos personagens e dos elementos de cena também deverá ser construída pelo caminho que os olhos percorrerem. Por esta dimensão espacial, o tempo está em suspensão.

A disposição paralela dos planos forma um conjunto de expressão, cujo referencial simbólico remete à nostalgia expressa pelas ruínas. No entanto, também é possível que os olhos percorram outros rumos e passeiem pela imagem, retornando aos mesmos pontos por diversas vezes. É possível que transitem em espiral, tomando um assunto como ponto central e descrevendo trajetórias do centro às bordas, ou delas ao centro, percorrendo a imagem de modo quase total. Este modo de ver em espiral retoma a memória das narrativas pré-corânicas: o assunto central da cena, ou seu motivo imagético, marca o ponto inicial da espiral, que se desenvolverá em correspondência

${ }^{5}$ Um dos três artistas seniores a ilustrar o Shah-nama (O "Livro dos Reis" da Pérsia, escrito durante o século X e ilustrado entre 1522 e 1530). Foi reconhecido por seus traços, que fluem suavemente, caracterizações agradáveis, arabescas generosamente arredondadas e cores harmoniosamente inventivas. 
com outros elementos de cena por seu posicionamento e intenção de movimento. Nesta forma, o desenvolvimento do enredo atualiza constantemente o significado de cada lugar e de cada cena vista anteriormente, dando a ela um sentido novo.

A forma espiralada está presente na memória do Islã como caminho percorrido pelo profeta Mohammad no Mi'raj Namah, que deixa a entender a possibilidade de atravessamento do mesmo ponto por diversas vezes, sendo que a cada retorno há uma miragem diversa, acrescida da experiência anterior. Mas este movimento, que não é original do Corão, diz muito do modo de narrar as histórias persas pré-islâmicas: os finais tendem a se confundir com o começo, distendendo a noção de causalidade e dilatando o tempo, pela marcação cíclica que o depõe de toda e qualquer ideia de finalidade; conhecemos as ações dos personagens, mas temos apenas indícios de suas motivações, ou mesmo dos resultados de suas investidas; este tempo, como também em Kirostami, é um tempo em meandros, inconcluso, composto por sentidos espiralados e ritualizados do olhar.

As iluminuras islâmicas materializam bem o sentido pretendido por Henry Corbin quando explana sobre o mundo imaginal, essa forma de entendimento que unifica no mesmo plano as dimensões sensível e inteligível, que integram os aspectos da Visão como sentido externo à Imaginação e dá confluência a esses dois oceanos em uma condição intermediária de existência. Este mundo imaginal, agente e inconcluso, expresso como memória da oralidade tribal da pérsia, configura-se em linhas paralelas nas iluminuras e constitui a memória visual apreendida nas imagens cinematográficas e fotográficas de Abbas Kiarostami da atualidade.

É o que o Islã chama alam al-mithâl, o mundo de malakût, que não é o mundo dos sentidos, mas também não é o mundo do puro entendimento abstrato. É povoado por realidades alheias à matéria sensível, mas possuidoras de forma e dimensão. É, segundo a fórmula sufi, o mundo em que se espiritualizam os corpos e se corporificam os espíritos. (PIMENTA, 2014, p.98, grifo do autor).

Desta arte é possível que se veja livremente a expressão iluminada como algo além daquilo que ela mostra, neste contexto, no qual uma árvore é uma árvore e, ao mesmo tempo, outra coisa, um sentido a mais, construído em inconclusa espiral. Ao percorrer a cena por diversas vezes, o olho apreende sua forma quase que em totalidade, internalizando naquele que vê uma visão total da cena, se aproximando do princípio de 
onividência dos planos divinos da observação. E se nos referimos à divindade, não podemos deixar de supor uma forma de divindade em que o homem figure como deus.

Esta sensação traduz o significado espacial do Barzah, o intermundo da espiritualidade persa, no qual diferentes camadas de tempo e espaço são experimentadas no mesmo ponto, como que dinamizando uma visão total que se configura como experiência. A visão total do Barzah na iluminura coordena a visão do espaço sem que suas camadas precisem ser subordinadas umas às outras.

Plano divino e humano sob o mesmo ponto, no qual o ente que observa, quando observa, vê também a si, é devolvido aos planos de sua própria existenciação, de seu ato de existir em potência criadora. O sentido é composto, no intermundo da imagem, com os olhos de um pelo outro em reciprocidade com a imagem que se dá a conhecer a ao olhar que se deixa conhecer nela. O intermundo é o limiar do além entre o sentido dos olhos e a superfície da forma, espaço no qual aquele que vê se locomove, não por meio dos membros externos do corpo, mas pela profundidade das sensações que experimenta.

Esta forma de experiência imaginal se manifesta no encontro com a imagem, com a palavra, com a presença transmutante de uma imagem interior. O percurso da imagem pelos dois polos, figura/palavra-olho, é o resultado de uma pedagogia visual que se traduz interiormente pelo encontro com a imagem interior. A possibilidade de uma presença total da imagem, sob esta ótica, significaria uma transfiguração de todos os sentidos pelos olhos e ouvidos interiores, estendendo uma espacialidade relacional: este é o mundo do filme, este é o espaço/sentimento no qual a fotografia poderia operar seus deslumbres de contemplação.

A imaginação ativa de Sohravardî se forma neste entre-dois do conhecimento com a fantasia, perdendo potência quando literalizada. Neste caso, a imaginação operaria por encaixes, colagens tais que o homem seria assombrado por pesadelos espantosos, seres de muitas cabeças ou imagens delirantes. Mas quando opera como mediadora, sem cismas, torna-se cogitativa e permite ao observador, até então isolado em seu canto, a experiência da contemplação.

Ao franquear esse limite, se faz como um tipo de inversão de tempo e espaço: o que estava oculto se abre e envelopa o exterior. Agora é o sentido sutil que contém a matéria e a forma. Neste ponto de relação, o que se vê não é mais situado em um local, mas situativo. É o espaço privilegiado do observador que se revela a si mesmo, que, ao ver, mostra sua própria paisagem (Xvarnah), transfigurando em dados simbólicos, as 
figuras vistas, a reproduzir as realidades próprias da visão. Penetrar aí é, pois, um êxtase, um deslocamento furtivo e uma mudança de estado.

\section{Considerações}

Em Através das Oliveiras, Kiarostami mostra o peregrino que, por muitas vezes, percebe como um maravilhamento a inquietude comunicada por um gosto estranho de desorientação, expatriamento. Esta sensação do Barzah, nas imagens das iluminuras, das histórias, desperta o espectador ativo como estrangeiro em seu próprio mundo e suscita a conjunção da bi-unidade da sua imagem interior com seu alter-ego exterior. Este processo relacional de alteridade diante da imagem/história, do outro, cria as condições de individuação, eclodindo a condição anteriormente polarizada. A contrapartida visual do espectador, o sentimento profundo de relação com o que é visto manifestam sua própria singularidade. O ser vidente torna-se estrangeiro em sua própria terra.

Este exercício reflexivo buscou integrar as fotografias de Kiarostami ao discurso que este diretor cria com sua própria produção artística, em termos de interpretá-las no contexto da cultura visual da qual emergem. Determinados sentimentos foram agitados para isso, reverberando possibilidades de inteiração entre a imagem e seu interlocutor visual. Há que se considerar o interlocutor para que o exercício de interpretação se alongue em significado. Este alongamento não tem um final determinado, talvez o sentimento da inconclusão pareça um incômodo em uma cultura habituada a exercícios intelectuais, cujo propósito esteja estabelecido prioritariamente. A necessidade de conhecer os enredos antes de iniciar os filmes, a necessidade de certeza quanto ao sentido atribuído às histórias, cujo final é claro e manifesto, são atributos de uma cultura visual moderna e ocidentalizada, melhor dizendo, partilham de um reino, cuja utilidade de emprego do tempo se faz forma e medida para "dispêndio de energia".

Não suportamos a condição de estrangeiridade posta pelo sentido transitório, aberto. Em geral, tendemos a preferir as estradas retas, os caminhos definidos e conhecidos de nossos percursos racionais e emocionais. Talvez a ausência de informações definidas nos assuste pelo medo da própria solidão, de sentar sozinho consigo e criar para si um rosto, ou um sentido. A perda desta capacidade ocasiona a perda da possibilidade de contemplação, esmaece a aura das coisas, tornando-a inacessível para nós. 
Por este e diversos outros motivos, o uso pedagógico das imagens tem se restringido ao potencial ilustrativo, a dar visibilidade a conceitos externos àqueles que surgem na singularidade da relação, inconclusa, entre quem vê e o que é visto. $\mathrm{O}$ importante, como traço fundamental da obra de Kiarostami, e de outros artistas, é o movimento que se desenrola no tempo, não a finalidade.

O movimento dos olhos sobre a imagem, em geral, traça o plano de visualidade ao qual correspondem os processos educativos sob os quais foram historicamente constituídos nossos hábitos e modos de olhar. Se, habitualmente, nossa cultura visual se constituiu pelo regramento, foi fomentada por regras e cânones de uma escola específica, aderimos.

Os olhos habituados à profundidade buscam no espaço o referencial de proporcionalidade nas dimensões e tamanhos dos elementos de cena para ordená-los na tridimensionalidade. Quando é necessário aos olhos, não só que os olhos refaçam seu padrão de ver, mas que busquem, na superfície da imagem, uma forma outra de dar sentido ao que veem, a tencionar a naturalidade objetiva do sentido da visão, algo de diferente se inicia aí. Criar sentido para a imagem fotográfica, expressa feito iluminura oriental, significa também alongar possibilidades para a incerteza e a inconclusão.

\title{
VISUAL MEMORY AND CREATIVE IMAGINATION IN KIAROSTAMI ROADS
}

\begin{abstract}
From the unrest feeling proportionated by the contact with images in which unfinished aspect stands the desire of rational organized understanding. This means that we start from a understanding that the interpretation is not exclusively based in the considered work, but in the formation of its creator and in the viewer. This article originated from the concern in propose ways to see the photography of Abbas Kiarostami (Teerã, 1940), that took into account the process of visual education produced by the Iranian Persian miniatures. We pass by the cinematographic and photographic images of this director and photographer, recognizing in the elements of its composition the distinctive attributes of the Persian miniatures and traditional narratives, resulting ways to see that they come from in the immersion of the visual memory of the artist and viewer.
\end{abstract}

Key words: Photography. Abbas Kiarostami (1940). Visual education. Creative imagination. Persian miniature. 


\section{REFERÊNCIAS}

ALMEIDA, M. J. Cinema: arte da memória. Campinas: Autores Associados, 1999.

ARABÎ, I. Alquimia da felicidade perfeita. Tradução de Roberto Ahmad Cattani. São Paulo: Landy, 2002.

BENJAMIN, W. Escritos sobre mito e linguagem (1915-1921). São Paulo: 34, 2011.

BENJAMIN, W. A obra de arte na época de suas técnicas de reprodução. In: BENJAMIN, W.; HORKHEIMER, M.; ADORNO, T. W.; HABERMAS, J. Textos escolhidos. Tradução de José Lino Grünnewald. 2. ed. São Paulo: Abril Cultural, 1983. p.5-34.

BERNARDET, J. C. Caminhos de Kiarostami. São Paulo: Cia. das Letras, 2004.

CORBIN, H. Cuerpo espiritual y tierra celeste: del Irán Mazdeísta al Irán Chiíta. 2. ed. Madrid: Ediciones Siruela, 2007.

CORBIN, H. L'Imagination créatrice dans le soufisme d'Ibn' Arabi. Paris: Entre Lacs, 2006.

GOSTO de cereja = T'am'e ghilass. Direção de Abbas Kiarostami. Irã: [s.n.], 1997. 1 videocassete (99 min.), color., $35 \mathrm{~mm}$.

ISHAGHPOUR, Y. O real, cara e coroa. In: ISHAGHPOUR, Y. Abbas Kiarostami. São Paulo: Cosac Naify, 2004. Mostra Internacional de Cinema de São Paulo. p. 85171.

KIAROSTAMI, A. As estradas de Kiarostami 1978-2003 e Duas ou três coisas que sei sobre mim. In: KIAROSTAMI, A. Abbas Kiarostami. São Paulo: Cosac Naify, 2004. Mostra Internacional de Cinema de São Paulo. p. 02-71.

LISSOVSKY, M. Pausa do destino: teoria, arte e história da fotografia. Rio de Janeiro: Mauad, 2014.

PIMENTA, A. V. A poética do olhar e o intermundo persa: imagens e palavras: homenagem a Milton José de Almeida. Campinas: Autores Associados, 2014.

O VENTO nos levará = Bad ma ra khahad bord. Direção de Abbas Kiarostami. Irã: [s.n.], 1999. 1 videocassete (118 min.), color., 35mm.

VIDA e nada mais, e a vida continua = Zendegi va Digar Hich. Direção de Abbas Kiarostami. Irã: [s.n.], 1992. 1 videocassete (91 min.), color., 35mm.

WELCH, S. C. Persian painting: five royal safavid manuscripts of the sixteenth century. New York: George Braziller, 1976. 